\title{
CINNAMIC ACID AND FISH FLOUR AFFECT WHEAT PHENOLIC ACIDS AND FLAVONOID COMPOUNDS, LIPID PEROXIDATION, PROLINE LEVELS UNDER SALT STRESS
}

\author{
Bergüzar Karadă̆ and Nilgün Candan YüCel* \\ Department of Chemistry, Faculty of Science, Dokuz Eylul University, \\ Buca, 35390, Izmir, Turkey \\ (Received: February 9, 2017; accepted: July 21, 2017)
}

\begin{abstract}
To elucidate the physiological mechanism of salt stress mitigated by cinnamic acid (CA) and fish flour (FF) pretreatment, wheat was pretreated with 20,50 and $100 \mathrm{ppm} \mathrm{CA}$ and $1 \mathrm{~g} / 10 \mathrm{~mL}$ FF for $2 \mathrm{~d}$ and was then cultivated. We investigated whether exogenous $\mathrm{CA}+\mathrm{FF}$ could protect wheat from salt stress and examined whether the protective effect was associated with the regulation of seed vigor, antioxidant defense systems, phenolic biosynthesis and lipid peroxidation. At 2 days exogenous CA did not influence seed vigor. Salt stress increased the phenolic biosynthesis, but the CA+FF-combined pretreatment enhanced the phenolic biosynthesis even more under salt stress and decreased lipid peroxidation to some extent, enhancing the tolerance of wheat to salt stress.
\end{abstract}

Keywords: Cinnamic acid - fish flour - phenolic biosynthesis - salinity stress - wheat

\section{INTRODUCTION}

Wheat and other crops are detrimentally affected from salt stress. When seeds are pretreated with a mild stress, their antioxidant enzyme activities such as superoxide dismutase (SOD, EC 1.15.1.1), catalase (CAT, EC 1.11.1.6), ascorbates-peroxidase (A-POD, EC 1.11.1.11), guaiacol-peroxidase (G-POD, EC 1.11.1.7) and as well as antioxidant metabolite levels (like ascorbates) are influenced. Many of these influences are believed to be adaptive responses by which wheat cope with salt stress. Salicylic, ferulic, caffeic and other phenolic acids can create initial stage of oxidative stress in plant metabolisms [25]. However, when the phenolic acids are applied exogenously at suitable concentrations, salicylic acid enhances the efficiency of the antioxidant defense and alleviates stress damage [12]. Cinnamic acid (CA) is one of phenolic acids and is a strong allelochemical that affects several metabolic processes and stimulates antioxidant defense enzymes activities [5]. Mostly, CA affects the plasma membrane and related different physiological processes, eventually including the induction of oxidative stress. Salvador et al. [22] showed that hydroxycinnamic acids impaired soybean root growth and induced lignifications. Cinnamic acid can

\footnotetext{
*Corresponding author; e-mail: nilgun.candan@deu.edu.tr
} 
also alleviate salt damage at the seedling stage [28]. Besides, its allelopathic action, $\mathrm{CA}$ is the first product of shikimate pathway and is consequently a precursor for flavonoid compounds. We hypothesized that pretreatment with CA and fish flour could enhance the ability of plants to alleviate high salt stress through changing seed vigor and the phenolic biosynthesis. Our work may contribute to elucidate the physiological mechanism of salt stress mitigated by exogenous cinnamic acid.

Anchovy (Engraulis encrasicholus) is the most abundant fish species in Black Sea of Turkey [3]. The fish waste during processing, including the head and other residues, represents over $60 \%$ of its production. Therefore, using edible fish waste becomes highly important for economy and environmental pollution [7]. Mechanically separated fish waste may be used to produce fish flour through drying. The amino acids of Turkish anchovy (72-74\% protein) found in higher quantity were glutamic acid (a proline precursor), proline, aspartic acids and arginine with respect to the species of other countries [10]. Fish flour contains sufficient concentrations of glutamic acid and proline in the plant cells; both amino acids may be involved in the regulation of phenolic synthesis via the phenylpropanoid pathway and fish flour a likely rich source for phenylpropanoid pathway product, might perform defense-related functions [24]. However, whether to regulate phenylpropanoid pathway synthesis by FF and CA no data have been reported. There are only a few studies about fish protein hydrolysates, which are different fisheries industry products [14]. Exogenous cinnamic acid (CA) and fish flour (FF), applied alone and also combined, on plant growth and development have received no attention under salt stress. The primary objective of this work was to analyze the effect of CA and FF on growth, and phenolic biosynthesis of wheat. Also determine whether exogenous elicitor may result in an increase in both biochemical (individual phenolic compounds, PAL, PODs (A-POD and G-POD), SOD and CAT enzyme activities, LPO levels and proline contents) and traditional agronomic indicators (germination percentage, shoot and root length) of seed vigor. High performance liquid chromatography (HPLC) analysis was done for separation and identification of major phenolic compounds of wheat. Increasing our understanding of such interactions will help both identify and address problems that arise in continuous cropping systems.

\section{MATERIALS AND METHODS}

\section{Plant material and seed treatment}

Ten g of wheat cultivar (Triticum durum Desf. cv. Yelken) seeds were transplanted into $10 \mathrm{~cm}$ pots with sand. They were cultivated $25^{\circ} \mathrm{C}$ with $25 \mu \mathrm{mol} \mathrm{m}^{-2} \mathrm{~s}^{-1}, 400-700$ $\mathrm{nm}$ and were watered regularly with Hoagland solution for $2 \mathrm{~d}$. Then plants divided five groups. One group of seedlings were pretreated with $20 \mathrm{ppm} \mathrm{CA}+1 \mathrm{~g} / 10 \mathrm{~mL} F F$, $50 \mathrm{ppm} \mathrm{CA}+1 \mathrm{~g} / 10 \mathrm{~mL} \mathrm{FF}, 100 \mathrm{ppm} \mathrm{CA}+1 \mathrm{~g} / 10 \mathrm{~mL}$ FF and other group did not pretreated. Then, two groups of CA+FF-pretreated wheat were exposed to separately to salt stress and normal conditions. Likely, two groups of non-pretreated wheat were 
exposed separately to salt stress and normal conditions. The salinity concentration is $150 \mathrm{mM}$ sodium chloride.

Fish flour (FF) was purchased from a local sardine fabric (Protein content 0.74 protein $\mathrm{g} / \mathrm{FF}$ g). Anchovy fish flour includes $90.76 \%$ dry matter, $9.86 \%$ glutamic acid, $7.48 \%$ aspartic acid, $6.31 \%$ lysine, $5.78 \%$ leucine, $4.89 \%$ proline and $4.41 \%$ arginine. It was sieved to obtain a homogeneous size particle of $0.84 \mathrm{~mm}$ and ground to reach particle size of $0.5 \mathrm{~mm}$.

\section{Germination percentage shoots length, and roots length}

Seeds were considered to be germinated when the radicle emerged through the seed coat and reached more than $2 \mathrm{~mm}$ in length. The number of germinated seeds for each cultivar and treatment was recorded every day. Germination percentages (GP) were calculated using the following equations: $\mathrm{GP}=n / \mathrm{N} \times 100 \%$, where $n$ is the number of germination, and $\mathrm{N}$ represents the total number of tested seeds. The weight of whole seedlings (roots included) was measured.

\section{Enzyme determinations}

For enzyme determination: one gram of germinating seeds and seedlings were grounded and homogenized in $4 \mathrm{ml}, 20 \mathrm{mM}$ phosphate buffer $(\mathrm{pH} 7.4)$ was containing $50 \mathrm{mM} \beta$-mercaptoethanol. The homogenate was filtered and then centrifuged at $15,000 \times \mathrm{g}$ for $15 \mathrm{~min}$. The enzymatic assay of phenylalanine ammonia-lyase (EC 4.3.1.5) activity was measured by Hodgins method [13]. Assay concentrations contained $150 \mathrm{mM}$ Tris-base $\mathrm{pH} 8.5$ buffers, $3 \mathrm{mM}$ L-phenylalanine and enzyme $\left(E=19.73 \mathrm{mM}^{-1} \mathrm{~cm}^{-1}\right)$.

Superoxide dismutase (EC 1.15.1.1) activity was determined by the Crosti method [9]. One unit of enzyme activity is defined as $50 \%$ inhibition of 6-hydroxydopamine (6-OHDA) auto oxidation under assay conditions. Ascorbate-peroxidase activity (EC 1.11.1.11) was measured according to Nakano and Asada [19] by monitoring the rate of ascorbate oxidation at $290 \mathrm{~nm}\left(E=2.8 \mathrm{mM}^{-1} \mathrm{~cm}^{-1}\right)$. The reaction mixture contained $25 \mathrm{mM}$ phosphate buffer ( $\mathrm{pH} 7.0$ ), $0.1 \mathrm{mM}$ EDTA, $1 \mathrm{mM} \mathrm{H}_{2} \mathrm{O}_{2}, 0.25 \mathrm{mM}$ AsA and the enzyme sample. No change in absorption was found in the absence of AsA in the test medium.

The guaiacol-peroxides (EC 1.11.1.7) activity assay was performed in a mixture of $25 \mathrm{mM}$ phosphate buffer ( $\mathrm{pH} 7.0$ ), $0.05 \%$ guaiacol, $10 \mathrm{mM} \mathrm{H}_{2} \mathrm{O}_{2}$, and enzyme. Activity was determined by the increase in absorbance at $470 \mathrm{~nm}$ due to guaiacol oxidation $\left(E=26.6 \mathrm{mM}^{-1} \mathrm{~cm}^{-1}\right)[19]$.

Catalase (EC 1.11.1.6) activity was assayed in a reaction mixture containing 25 $\mathrm{mM}$ hosphate buffer ( $\mathrm{pH}$ 7.0) $10.5 \mathrm{mM} \mathrm{H}_{2} \mathrm{O}_{2}$ and enzyme in $25 \mathrm{mM}$ phosphate buffer ( $\mathrm{pH}$ 7.0). The decomposition of $\mathrm{H}_{2} \mathrm{O}_{2}$ was followed at $240 \mathrm{~nm}\left(E=39.4 \mathrm{mM}^{-1}\right.$ $\left.\mathrm{cm}^{-1}\right)[2]$. 


\section{Analytical methods}

Proline content was determined as follows [4]. Five mg tissue was weighed and added to $3 \%, 1.2 \mathrm{ml}$ of sulphosalicylic acid to precipitate protein. The samples were centrifuged at $18,000 \times g$ for $15 \mathrm{~min}$ and then supernatant was diluted 1:1 with distilled water. Thereafter, $1 \mathrm{ml}$ glacial acetic acid and $1 \mathrm{ml}$ ninhydrin reagent [prepared 3\% $(\mathrm{w} / \mathrm{v})$ ninhydrin in $60 \%(\mathrm{v} / \mathrm{v}) 6 \mathrm{M}$ phosphoric acid] added. Tubes kept for $1 \mathrm{~h}$ at $90{ }^{\circ} \mathrm{C}$ after cooling in ice. The products were extracted with $2 \mathrm{ml}$ of toluene, then mixed by vortex. Solvent decanted into a glass cuvette and absorbance read at $520 \mathrm{~nm}$.

Total phenolic content in wheat samples were taken on first, third, fifth day of germination and was determined according to McCue method and gallic acid (25-200 $\mu \mathrm{g} / \mathrm{mL}$ ) was used as a phenolic standard curve [18]. The flavonoid content in the crude extract was determined according to the method [11] of Du and co-workers with some modifications. A series of standards of rutin in the range of $10-80 \mu \mathrm{g} / \mathrm{mL}$ were prepared in $30 \%$ ethanol solution.

Ascorbate concentrations were immediately determined by the 2,4-dinitrophenylhydrazine [20]. The sample absorbance was measured at wavelengths $460 \mathrm{~nm}$.

LPO was estimated based on thiobarbituric acid (TBA) reactivity [8]. The protein content was determined by Bradford-method using bovine serum albumin (BSA) as a standard [6].

\section{Quantitative analysis of individual phenolic compounds by HPLC}

The phenolic acids and rutin standard solution were prepared at $1 \mathrm{mg} / \mathrm{mL}$ in methanol. They were diluted into seven concentrations $(5.0,2.5,1.0,0.5,0.25,0.125$ and 0.0625 $\mu \mathrm{g} / \mathrm{mL})$ for a calibration curve. Each extract was dissolved in methanol $(1 \mathrm{mg} / \mathrm{mL})$. All solutions were filtered through a $0.2 \mathrm{~mm}$ membrane filter. Samples were extracted as described by Lee and Scagel [16] with some modifications. $0.5 \mathrm{~g}$ dried wheat shoot tissues was ground in a mortar with acidified methanol $(0.1 \%$ formic acid, $\mathrm{v} / \mathrm{v})$ and were waited in a boiling water bath for $5 \mathrm{~min}$, then immediately kept in ice bath for $10 \mathrm{~min}$. All the mixtures were filtered through Whatman-paper and the pellet was reextracted. Analyses were carried out using Agilent 1100 HPLC system with a UV detector (Agilent Technologies, CA, USA). Samples were separated on C18 Kinetex column $(100 \times 2.1 \mathrm{~mm})$ with $2.6 \mu \mathrm{m}$ particle size. The mobile phase consisted of eluent A: $0.1 \%$ TFA diluted in water and eluent B: acetonitirile. The absorbance of the eluent was scanned at $280 \mathrm{~nm}$ by the UV.

\section{Statistical analysis}

Tukey-test, one of the multiple comparisons, was used for statistical significance analysis. The data reported in this paper are the mean $\pm \mathrm{SD}$ of three independent experiments, or 3-4 replicates of biochemical tests. Also comparison was made with Pearson-correlation for each substrate and/or enzyme. 


\section{RESULTS}

\section{Growth parameters}

In this study, wheat was pretreated with $\mathrm{CA}+\mathrm{FF}$ and then exposed to salt stress. It was also investigated CA-alone pretreatment. However, we observed that the four growth data (Germination\%, FW, SL and RL) showed no significant difference $(p>0.01)$ between the CA-pretreated and untreated (control) seedlings. At $3 \mathrm{~d}$ after the start of the experiment, wheat seedlings had been subjected to salt stress for $9 \mathrm{~d}$. Percentage of seed germination, shoot-root lengths and also fresh weight of $\mathrm{CA}+\mathrm{FF}-\mathrm{combined}$ treatment were investigated (data not shown). The level of germi-

Table 1

Total phenolic and flavonoid contents of wheat for different treatments; control, non-saline control and 20,50, $100 \mathrm{ppm}$ cinnamic acid $+1 \mathrm{~g} / 10 \mathrm{~mL}$ fish flour-combined treatment under salt stress $150 \mathrm{mM} \mathrm{NaCl}$

\begin{tabular}{|c|c|c|c|c|c|}
\hline & \multirow{2}{*}{$\begin{array}{l}\text { Salinity } \\
\mathrm{mM}\end{array}$} & \multirow{2}{*}{$\begin{array}{c}\text { Treatments } \\
(\mathrm{ppm}+\mathrm{g} / 10 \mathrm{~mL})\end{array}$} & \multicolumn{3}{|c|}{ Wheat Organs } \\
\hline & & & Shoot & Root & Seed \\
\hline \multirow{10}{*}{$\begin{array}{l}\text { Total soluble } \\
\text { phenolic content } \\
\left(\mathrm{mg} \mathrm{g}^{-1} \mathrm{FW}\right)\end{array}$} & \multirow{5}{*}{0} & Control & $13.5 \pm 1.4$ & $7.6 \pm 0.8$ & $8.8 \pm 0.2$ \\
\hline & & $\mathrm{FF}$ & $14.3 \pm 1.1$ & $8.9 \pm 1.0$ & $9.3 \pm 0.7$ \\
\hline & & $20 \mathrm{CA}+\mathrm{FF}$ & $18.3 \pm 2.0^{\varepsilon}$ & $14.1 \pm 0.6^{\varepsilon}$ & $13.5 \pm 0.5^{\varepsilon}$ \\
\hline & & $50 \mathrm{CA}+\mathrm{FF}$ & $16.2 \pm 0.7^{\varepsilon}$ & $10.3 \pm 1.1^{\varepsilon}$ & $10.1 \pm 0.2^{\varepsilon}$ \\
\hline & & $100 \mathrm{CA}+\mathrm{FF}$ & $15.1 \pm 0.7^{\varepsilon}$ & $9.3 \pm 0.9^{\varepsilon}$ & $9.2 \pm 0.1^{\varepsilon}$ \\
\hline & \multirow{5}{*}{150} & Control (Salt stress) & $14.1 \pm 2.4$ & $10.2 \pm 1.2$ & $10.7 \pm 0.6$ \\
\hline & & $\mathrm{FF}$ & $13.5 \pm 1.7$ & $10.5 \pm 1.5$ & $10.5 \pm 0.9$ \\
\hline & & $20 \mathrm{CA}+\mathrm{FF}$ & $12.3 \pm 3.2^{\varepsilon}$ & $11.0 \pm 1.8$ & $9.8^{8} \pm 0.5^{\varepsilon}$ \\
\hline & & $50 \mathrm{CA}+\mathrm{FF}$ & $13.3 \pm 2.2^{\varepsilon}$ & $10.1 \pm 0.9^{\delta}$ & $10.1 \pm 0.4$ \\
\hline & & $100 \mathrm{CA}+\mathrm{FF}$ & $12.8 \pm 1.6^{\varepsilon}$ & $10.5 \pm 1.5^{\delta}$ & $9.9 \pm 0.7^{\varepsilon}$ \\
\hline \multirow{10}{*}{$\begin{array}{l}\text { Total flavonoid } \\
\text { content } \\
\left(\mu \mathrm{g} \mathrm{g}^{-1} \mathrm{FW}\right)\end{array}$} & \multirow{5}{*}{0} & Control & $15.5 \pm 1.2$ & $14.0 \pm 0.3$ & $65.3 \pm 2.5$ \\
\hline & & $\mathrm{FF}$ & $16.2 \pm 1.7$ & $13.8 \pm 1.0$ & $75.2 \pm 1.3$ \\
\hline & & $20 \mathrm{CA}+\mathrm{FF}$ & $18.2 \pm 1.1^{\varepsilon}$ & $15.6 \pm 1.1^{\varepsilon}$ & $91.2 \pm 2.5^{\delta}$ \\
\hline & & $50 \mathrm{CA}+\mathrm{FF}$ & $17.5 \pm 1.3^{\varepsilon}$ & $14.5 \pm 1.3^{\delta}$ & $81.0 \pm 3.2^{\varepsilon}$ \\
\hline & & $100 \mathrm{CA}+\mathrm{FF}$ & $16.8 \pm 1.5^{\varepsilon}$ & $13.5 \pm 1.1^{\varepsilon}$ & $76.0 \pm 4.1^{\varepsilon}$ \\
\hline & \multirow{5}{*}{150} & Control (Salt stress) & $17.6 \pm 1.3$ & $14.3 \pm 1.3$ & $97.2 \pm 7.6$ \\
\hline & & $\mathrm{FF}$ & $17.9 \pm 0.9$ & $13.2 \pm 0.7$ & $96.2 \pm 5.8$ \\
\hline & & $20 \mathrm{CA}+\mathrm{FF}$ & $18.5 \pm 1.3$ & $14.6 \pm 1.3$ & $96.2 \pm 9.5^{\delta}$ \\
\hline & & $50 \mathrm{CA}+\mathrm{FF}$ & $18.8 \pm 1.3^{\delta}$ & $13.2 \pm 1.3^{\delta}$ & $95.7 \pm 4.4^{\varepsilon}$ \\
\hline & & $100 \mathrm{CA}+\mathrm{FF}$ & $16.6 \pm 1.3^{\varepsilon}$ & $13.9^{\prime} \pm 1.3^{\varepsilon}$ & $94.9 \pm 9.1^{\varepsilon}$ \\
\hline
\end{tabular}

Data are the mean \pm SD of three independent experiments.

${ }^{\delta} p<0.05$ (probably significant).

${ }^{\varepsilon} p<0.01$ (definitely significant). 
nation percentages and fresh weights in wheat seedlings grown under salt stress increased from day 1 to 9 in absence as well as in the presence of CA+FF treatment. However, the germination percentage was gradually and significantly reduced by salt stress and CA-pretreatment. In the $\mathrm{CA}+\mathrm{FF}$ treatment group, the four growth data were higher than those in salt treatment group (data not shown). Salt stress decreased the fresh weight and germination rate from $117 \pm 3$ to $90 \pm 6 \mathrm{mg}$ and from 90 to $70 \%$ on the 9th day $(p<0.01)$, respectively. However, the levels were alleviated by $\mathrm{CA}+\mathrm{FF}$ pretreatment under both non-saline conditions and salt stress. Application of salt stress decreased the root and shoot length from $4.9 \pm 0.8$ to $3.6 \pm 0.6 \mathrm{~cm}$ and from $6.8 \pm 0.8$ to $4.7 \pm 0.6 \mathrm{~cm}$ on the 9 th day, respectively. However, the length of wheat seedlings grown from $\mathrm{CA}+\mathrm{FF}$-combined pre-treatment induced significantly nonsaline conditions and salt stress $(p<0.05)$ (data not shown).

\section{The total phenolic and flavonoid content}

FF pretreatment showed no significant differences of the total phenolic and flavonoid content $(p>0.01)$. Applied CA + FF-combined pretreatment in the order of increasing total phenolic and flavonoid contents of the wheat seedlings organs were root $<$ shoot $<$ seed, respectively. The flavonoid contents increased more under salt stress when compared to none-saline condition. The maximum increase of the total phenolic and flavonoid contents under salt stress were determined as 1.4-, 1.9- and 1.5-fold; 1.2-, 1.1- and 1.4-fold increases of CA+FF combined pre-treatment as compared to nonsaline control for shoot, root and seed, respectively $(p<0.01)$ (Table 1$)$.

Table 2 shows PAL, PODs, SOD and CAT enzyme activities and also proline, ascorbate and LPO levels of shoots under both non-saline and salt stress condition on

Table 2

Parameters: LPO and proline content, PAL and Gua-dep POD activities; control, and 20 ppm cinnamic acid $+(\mathrm{g} / 10 \mathrm{~mL})$ fish flour-combined treatment under salt stress $150 \mathrm{mM} \mathrm{NaCl}$ on the $9^{\text {th }}$ day

\begin{tabular}{|c|c|c|c|}
\hline \multirow{2}{*}{ Parameter } & Non-saline & Salt stress & Non-saline \\
\hline & Control & $20 \mathrm{ppm} \mathrm{CA}+\mathrm{FF}$ & $20 \mathrm{ppm} \mathrm{CA}+\mathrm{FF}$ \\
\hline PAL (U mg ${ }^{-1}$ protein) & $20 \pm 1$ & $45 \pm 2$ & $38 \pm 3^{\varepsilon}$ \\
\hline G-POD (U mg ${ }^{-1}$ protein) & $0.4 \pm 0.1$ & $6.5 \pm 1.1$ & $2.5 \pm 0.3^{\varepsilon}$ \\
\hline A-POD (U mg-1 protein) & $6.3 \pm 1.1$ & $8.2 \pm 1.0$ & $7.3 \pm 1.5$ \\
\hline SOD (U mg ${ }^{-1}$ protein $)$ & $35.7 \pm 2.5$ & $75.8 \pm 3.5$ & $53.2 \pm 1.1$ \\
\hline CAT (U mg ${ }^{-1}$ protein $)$ & $12.5 \pm 1.2$ & $30.2 \pm 2.2$ & $20.8 \pm 2.3$ \\
\hline LPO (nmol MDA g g-1) & $1.1 \pm 0.1$ & $0.8 \pm 0.1$ & $1.2 \pm 0.0^{\varepsilon}$ \\
\hline Ascorbate (mM) & $10.1 \pm 1.7$ & $18.2 \pm 1.1$ & $15.2 \pm 2.1$ \\
\hline Proline $\left(\mu \mathrm{mol} \mathrm{g}^{-1} \mathrm{FW}\right)$ & $2.2 \pm 0.1$ & $2.5 \pm 0.6$ & $4.5 \pm 0.1^{\varepsilon}$ \\
\hline
\end{tabular}

Data are the mean $\pm \mathrm{SD}$ of three independent experiments.

${ }^{\delta} p<0.05$ (probably significant).

${ }^{\varepsilon} p<0.01$ (definitely significant). 
Table 3

$20 \mathrm{ppm} \mathrm{CA}+(\mathrm{g} / 10 \mathrm{~mL})$ fish flour-combined treatment under non-saline and salt stress on the content of individual phenolic compounds in the shoot of wheat

\begin{tabular}{|l|c|c|c|}
\hline \multirow{2}{*}{ Phenolic compunds $\left(\mu \mathrm{g} \mathrm{g}^{-1}\right)$} & Non-saline & Salt stress & Non-saline \\
\cline { 2 - 4 } & Control & $20 \mathrm{ppm} \mathrm{CA}+\mathrm{FF}$ & $20 \mathrm{ppm} \mathrm{CA+FF}$ \\
\hline Rutin & $76.3 \pm 1.4$ & $58.0 \pm 9.2^{\varepsilon}$ & $61.9 \pm 12.1$ \\
\hline Scopelletin & $60.9 \pm 1.8$ & $116.6 \pm 7.3^{\varepsilon}$ & $45.4 \pm 0.5^{\varepsilon}$ \\
\hline Syringic acid & $57.6 \pm 5$ & $143.7 \pm 15.3^{\varepsilon}$ & $59.7 \pm 11.3^{\delta}$ \\
\hline Gallic acid & $57.7 \pm 11.2$ & $138.8 \pm 10.3^{\varepsilon}$ & $255.8 \pm 1.5^{\delta}$ \\
\hline Salicylic acid & $6.0 \pm 1.2$ & $5.1 \pm 0.5^{\varepsilon}$ & $7.4 \pm 0.3$ \\
\hline
\end{tabular}

Data are the mean \pm SD of three independent experiments.

${ }^{\delta} p<0.05$ (probably significant)

${ }^{\varepsilon} p<0.01$ (definitely significant).

the 9th day. Salt stress markedly increased PAL, PODs, SOD and CAT enzyme activities and also proline, ascorbate, LPO levels $(p<0.01)$. It is considered that the activity of these enzymes activities are more increased as a result of exposure to salt stress. The $20 \mathrm{ppm}$ CA+FF combined pretreatment appeared to be the most effective treatment in counteracting the negative effects of salt stress on PAL, SOD and PODs enzyme activities.

Scopoletin, rutin and phenolic acids such as syringic, gallic, salicylic acids were identified in the shoot of seedlings and quantified using HPLC (Table 3). $\mathrm{CA}+\mathrm{FF}$-combined priming did not cause a significant increase in the level of endogenous rutin and scopoletin under non-saline conditions. Thus, exogenous $\mathrm{CA}+\mathrm{FF}$ may be metabolized as precursors for some phenolic acids under non-saline conditions and may not be metabolized as precursors of flavonoids. Salicylic acids and also rutin in the shoot of seedlings priming with $\mathrm{CA}+\mathrm{FF}$ did not change significantly under salt stress $(p<0.01)$. However, Scopoletin, syringic and gallic acid were increased more than 2-fold in the shoot of seedlings priming with $\mathrm{CA}+\mathrm{FF}$.

\section{DISCUSSION}

Our findings showed that cinnamic acid did not affect wheat growth significantly. But, CA+FF-combined treatment increased wheat growth parameter at $20 \mathrm{ppm}$ CA levels. Low concentrations of phenolic acids such as benzoic acid and cinnamic acid have been shown to promote growth of cucumber seedlings, whereas high concentrations can inhibit plant growth [27]. Also, $\mathrm{Ng}$ et al. observed that $\mathrm{CA}$ at $1.0 \mathrm{mM}$ concentration significantly reduced canola's FW, shoot and root length. Unfortunately, little is known about its mode of action at the plant cellular level. The combined effect of CA and FF pretreatment decreased the MDA levels when compared to salt stress treatment alone. This is a similar result to that reporting on paraquat pretreatment resulting in a similar correlation between less damage to membranes and accumula- 
tion of less ROS [17], and thus, like our study, referring to improvement of the tolerance of wheat to salt stress. There were strong synergistic effects between cinnamic acid and fish flour on wheat quality along with strongly increasing phenolic biosynthesis. This implies that cinnamic acid or salinity itself could not satisfy all the demands of wheat phenolic production for available growth parameters. The germination percentage and fresh weight were reduced under salt stress. The root and shoot lengths also decreased under salt stress in the course of the treatment period and reached their minimum (by a 1.4-fold decrease) on the 9th day, respectively. Cinnamic acid (as a phenolic acid) is as signal molecule, has been shown to have significantly positive effects of plant adaptation against salt stress when combined with fish flour.

PAL is a key enzyme of the secondary metabolism pathway. The activity was induced in response to the high salt stress. However, CA+FF-combined pretreated seedlings maintained higher activity of PAL, as compared to the non-saline control. Similarly, Abu El-Soud et al. [1] demonstrated that chickpea seedlings pretreated with ellagic acid showed PAL higher activity under osmotic stress relative to the untreated seedlings. In agreement with PAL activity, the results showed that CA+FF-combined pretreated seedlings could accumulate significantly higher level of total flavonoids in response to NaCl-stress as compared with the untreated seedlings. Salt stress also induced the accumulation of flavonoids in wheat seedlings either in the absence or presence of CA. Nevertheless CA+FF-combined pretreated seedlings accumulated significantly higher amount of flavonoids under salt stress. Accumulation of phenolic, flavonoid and ascorbates can inhibit lipid peroxidation, where they were proven to trap the lipid alkoxy radicals depending on their structure [17]. Phenolic compounds limit the diffusion of free radicals to the hydrophobic matrix of the membrane and limit the peroxidative reactions in the hydrophobic region of the bilayer [26].

Our results also indicated that the elevated level of antioxidants (ascorbate) and antioxidant enzymes (SOD, CAT, PODs), and the low extent of lipid peroxidation were symptomatic for tolerance mechanism against salt stress. SOD is the major scavenger of $\mathrm{O}_{2}^{-}$in the defense systems. In our study, the observed increase in the SOD activity of wheat seedlings constituted the first line of defense via detoxification of superoxide anion radicals. Both CAT and SOD activities of CA +FF treated wheat seedlings were increased approximately by 2.0 -fold under salt stress and these activities correlated positively with each other. Moreover, SOD, CAT, A-POD and G-POD displayed a co-operative action for preventing a partial protection against salt stress under $\mathrm{CA}+\mathrm{FF}$ treatment. There is a strong correlation between salt tolerance (via lower LPO levels) and antioxidant enzyme activities (SOD, CAT, PODs), especially under $\mathrm{CA}+\mathrm{FF}$ exposure.

Exogenous $\mathrm{CA}+\mathrm{FF}$ may be metabolized as precursors for some phenolic acids, especially gallic acid (2.4-fold increase) and syringic acid (2.5-fold increase), under salt stress. This explanation may be supported by the detected six-fold accumulation of gallic acid in the shoot of FF $+\mathrm{V}$ primed wheat seedlings in an another study of ours. In this connection, gallic acid had been reported to accumulate in fruit of strawberry subjected to salt stress [15]. The major detected phenolic acids in wheat shoot were syringic and gallic acids, while salicylic acid was less abundant. These results 
are in accordance with previous studies obtained on wheat phenolome [23]. In addition to phenolic acids, scopoletin, level was increased (1.9-fold increase) in seedlings exposed to salt stress. Similarly, Saleh and Madany [23] had declared that coumarin priming has resulted in accumulation of scopoletin in the leaves of wheat.

Regardless of salt stress, similar to our studies, coumarin priming has resulted in significant accumulation of detected free phenolic acids. Saleh and Madany [23] only found that chlorogenic and caffeic acids decreased after coumarin priming. These results could suggest a direct role of CA in the regulation of shikimic acid biosynthetic pathway. Moreover, the accumulated phenolic acid, flavonoid and flavonoid precursors, in response to CA pretreatment, could improve the non-enzymatic antioxidant capacity as they are known for their free radical scavenging capacity. It is well known that salicylic acid has a multiple role in modulating the growth and metabolism of plant suffering abiotic stresses such as salinity. Thereby, the slightly accumulation of salicylic acid in the shoot of salt stressed wheat was observed. $\mathrm{CA}+\mathrm{FF}$ pre-treatment stimulated the POD activity as compared with the non-saline control. Such enhancement in POD activity could contribute to the antioxidant storage via scavenging $\mathrm{H}_{2} \mathrm{O}_{2}$ and provide oxidized substrates for some physiological processes.

Data presented in this study suggest the ability of cinnamic acid to improve wheat tolerance to salinity. The growth mitigating effect of $\mathrm{CA}+\mathrm{FF}$ on wheat seedling could be attributed to the remarkable accumulation of proline that could decrease the cellular osmotic potential and allow the root to absorb sufficient amount of water to maintain cell turgidity and improve plant growth especially via inducing phenolic biosynthesis under salt stress. The accumulated free phenolics and flavonoids improved the antioxidant defines system either directly by acting as antioxidant molecules or indirectly by serving as substrates for POD, and consequently help in scavenging of $\mathrm{H}_{2} \mathrm{O}_{2}$. According the our results cinnamic acid and fish flour can activate induced defence processes against the harmful effect of salt stress.

\section{ACKNOWLEDGMENT}

We would like to thank the Dokuz Eylul University for their financial support.

\section{REFERENCES}

1. Abu El-Soud, W., Hegab, M. M., Abdelgawad, H., Zinta, G., Asard, H. (2013) Ability of ellagic acid to alleviate osmotic stress on chickpea seedlings. Plant Physiol. Biochem. 71, 173-183.

2. Aebi, H. E. (1983) Catalase. In: Bergmeyer, H. U. (ed.), Methods of Enzymatic Analysis, vol. 3. Verlag Chemice, Deerfield Beach FL, pp. 273-286.

3. Anonymus (2000) Fisheries statistics. State Institute of Statistics, Prime Ministry, Republic of Turkey, Ankara.

4. Bates, L., Waldren, R. P., Teare, I. D. (1973) Rapid determination of free proline for water-stress studies. Plant Soil 39, 205-207.

5. Baziramakenga, R., Leroux, G. D., Simard, R. R. (1995) Effects of benzoic and Cinnamic acids on membrane permeability of soybean roots. J. Chem. Ecol. 21, 1271-1285. 
6. Bradford, M. M. (1976) A rapid and sensitive method for quantification of microgram quantities of protein utilizing the principle of protein-dye binding. Anal. Biochem. 72, 248-254.

7. Boscolo, W. R. (2001) Desempenhoe caracteristicas de carcaqa de machos revertidos de tilapias do Nilo (Oreochromisniloticus), linhagens tailandesa e comumnas fases iniciais e de crescimento. Revista Brasileire Zootec. 30, 1391-1396.

8. Buege, J. A., Aust, S. D. (1978) Microsomal lipid peroxidation. Methods Enzymol. 52, 302-310.

9. Crosti, N., Serviden, T., Bajer, J., Serra, A. (1987) Modification of 6-hydroxydopamine technique for the correct determination of superoxide dismutase. J. Clin. Chem. Clin. Biochem. 25, 265-272.

10. Dincer, T., Cakli, S., Kilinc, B., Tolasa, S. (2010) Amino acids and fatty acid composition content of fish sauce. J. Animal Vet. Advan. 9, 311-315.

11. Du, L., Ali, G. S., Simons, K. A., Hou, J., Yang, T., Reddy, A. S., Poovanah, B. W. (2009) Ca ${ }^{2+/}$ calmodulin regulates salicylic-acid-mediated plant immunity. Nature 457, 1154-1158.

12. Hayat, Q., Hayat, S., Irfan, M., Ahmad, A. (2010) Effect of exogenous salicylic acid under changing environment: a review. Environ. Exp. Bot. 68, 14-25.

13. Hodgins, D. S. (1971) Yeast phenylalanine ammonia-lyase. Purification, properties, and the identification of catalytically essential dehydroalanine. J. Biol. Chem. 246, 2977-2985.

14. Horii, A., McCue, P., Shetty, K. (2007) Seed vigour studies in corn, soybean and tomato in response to fish protein hydrolysates and consequences on phenolic-linked responses. Bioresource Technol. 98, 2170-2177.

15. Keutgen, A. J., Pawelzik, E. (2008) Quality and nutritional value of strawberry fruit under long term salt stress. Food Chem. 107, 1413-1420.

16. Lee, J., Scagel, C. F. (2009) Chicoric acid found in basil (Ocimum basilicum L.) leaves. Food Chem. $115,650-656$.

17. Milic, B.L., Dijilas, S. M., Canadanovic-Brunet, J. M. (1998) Antioxidative activity of phenolic compounds on metal-ion breakdown of lipid peroxidation system. Food Chem. 61, 443-447.

18. McCue, P., Zheng, Z., Pinkham, J. L., Shetty, K. (2000) A model for enhanced pea seedling vigour following low $\mathrm{pH}$ and salicylic acid treatments. Process Biochem. 35, 600-613.

19. Nakano, Y., Asada, K. (1981) Hydrogen peroxide is scavenged by ascorbate-specific peroxidase in spinach chloroplasts. Plant Cell Physiol. 22, 867-880.

20. Nino, H. V., Shaw, W. (1976) Determination of ascorbic acid. In: Tietz, N. W. (ed.), Vitamins Fundamental of Clinical Chemistry. pp. 542-550.

21. Ng, P. L., Ferrarese, M. L. L., Huber, D. A., Ravagnani, A. L. S., Ferrarese-Filho, O. (2003) Canola (Brassica napus L.) seed germination influenced by cinnamic acid and benzoic acids and derivatives: effects on peroxidase. Seed Sci. Technol. 31, 39-46.

22. Salvador, V. H., Lima, R. B., Dantas dos Santos, W., Soares, A. R., Böhm, P. A. F., Marchiosi, R., Ferrarese, M. L. L., Ferrarese-Filho, O. (2013) Cinnamic Acid Increases Lignin Production and Inhibits Soybean Root Growth. PLOS ONE 8, e69105, doi:10.1371/journal.pone.0069105.

23. Saleh, A. M., Madany, M. M. Y. (2015) Coumarin pretreatment alleviates salinity stress in wheat seedlings. Plant Physiol. Biohem. 88, 27-35

24. Shetty, K. (1997) Biotechnology to harness the benefits of dietary phenolics; focus on Lamiaceae. Asia Pacific J. Clin. Nutr. 6, 162-171.

25. Singh, H. P., Kaur, S., Batish, D. R., Kohli, R. K. (2009) Caffeic acid inhibits in vitro rooting in mung bean [Vigna radiata (L.) Wilczek] hypocotyls by inducing oxidative stress. Plant Growth Regul. 57, 21-30.

26. Verstraeten, S. V., Keen, C. L., Schmitz, H. H., Fraga, C. G., Oteiza, P. L. (2003) Flavan-3-ols and procyanidins protect liposomes against lipid oxidation and disruption of the bilayer structure. Free Radic. Biol. Med. 34, 84-92.

27. Wu, F. Z., Pan, K., Zhou, X. Y. (2005) Effects of Cinnamic acid on physiological characteristics of Cucumis sativus seedling. Chin. J. Appl. Ecol. 16, 915-918.

28. Zhang, J. Y., Wu, F. Z. (2007) Effects of salt stress on membrane lipid peroxidation and proline content in cucumber cultivars. China Vegetables 7, 12-15. 